\title{
Global pattern and trend of liver cancer survival: a systematic review of population-based studies
}

\author{
Yu-Fei Jiang ${ }^{1,2,3}$, Zhuo-Ying Li ${ }^{1,2}$, Xiao-Wei Ji1,2, Qiu-Ming Shen ${ }^{1,2}$, Jia-Yi Tuo ${ }^{1,2}$, Hui-Yun Yuan ${ }^{3}$, Yong-Bing \\ Xiang ${ }^{1,2,3}$ \\ 'School of Public Health, Shanghai Jiaotong University School of Medicine, Shanghai 200025, China. \\ ${ }^{2}$ State Key Laboratory of Oncogene and Related Genes \& Department of Epidemiology, Shanghai Cancer Institute, Renji Hospital, \\ Shanghai Jiaotong University School of Medicine, Shanghai 200032, China. \\ ${ }^{3}$ Renji Hospital, Shanghai Jiaotong University School of Medicine, Shanghai 200032, China.
}

Correspondence to: Prof. Yong-Bing Xiang, State Key Laboratory of Oncogenes and Related Genes \& Department of Epidemiology, Shanghai Cancer Institute, Renji Hospital, Shanghai Jiaotong University School of Medicine, No. 25, Lane 2200, Xie Tu Road, Shanghai 200032, China. E-mail: ybxiang@shsci.org

\begin{abstract}
How to cite this article: Jiang YF, Li ZY, Ji XW, Shen QM, Tuo JY, Yuan HY, Xiang YB. Global pattern and trend of liver cancer survival: a systematic review of population-based studies. Hepatoma Res 2020;6:52.

http://dx.doi.org/10.20517/2394-5079.2020.47
\end{abstract}

Received: 3 May 2020 First Decision: 1 Jun 2020 Revised: 15 Jun 2020 Accepted: 28 Jun 2020 Published: 15 Aug 2020

Academic Editor: Guang-Wen Cao Copy Editor: Cai-Hong Wang Production Editor: Jing Yu

\begin{abstract}
Aim: To describe the global pattern and trend of liver cancer survival, using data from the population-based studies or cancer registration.
\end{abstract}

Methods: By searching CNKI, Wanfang Data, PubMed, Web of Science, EMBASE and SEER. All population-based survival studies of liver cancer from 1 January 2000 to 30 April 2020 were collected and evaluated by patient gender, time period, and country. The overall or age-standardized five-year relative survival rate was used to describe the pattern and changes in liver cancer survival over the past decades.

Results: Globally, the highest age-standardized five-year relative survival rate was observed in Italy $(18.0 \%, 2005$ 2007) and the highest overall five-year relative survival rate was observed in Korea (34.6\%, 2012-2016), when compared to other countries. The most remarkable increase in overall five-year relative survival rate can be seen in Korea (from 10.7\% during 1993-1995 to 34.6\% during 2012-2016). In general, worldwide, the five-year relative survival rate of younger patients with liver cancer was higher than old people. For most countries, the five-year relative survival rate of liver cancer was slightly higher in women than in men. In China, the overall five-year relative survival rate of liver cancer in Taiwan was higher than that in other areas, while Cixian of Hebei and Qidong of Jiangsu were lower.

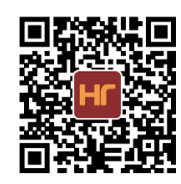


Conclusion: Over the past decades, the survival rates of liver cancer have gradually improved, but great variations are also observed globally. Worldwide, younger patients with liver cancer have experienced a better prognosis. Gender disparity in liver cancer survival was not obvious.

Keywords: Primary liver cancer, relative survival rate, prognosis, population-based study, cancer registration

\section{INTRODUCTION}

Primary liver cancer (PLC) is the sixth most common cancer and the fourth most common cause of cancer death worldwide ${ }^{[1]}$. The top five countries with the highest incidence of liver cancer are Mongolia $(71.8 / 100,000)$, Thailand $(33.7 / 100,000)$, North Korea $(32.3 / 100,000)$, Japan $(27.9 / 100,000)$, and China $(27.6 / 100,000)^{[2]}$. In the United States, the incidence has increased rapidly by $2 \%$ to $3 \%$ per year from 2007 to 2016, although the change was smaller than that in previous years ${ }^{[3]}$. According to Global cancer statistics $2018^{[1]}$, an estimated 841,080 incident cases of liver cancer occurred worldwide, with 392,868 in China, accounting for $46.71 \%$.

Certainly, incidence, mortality, and prevalence are commonly applied to describe the burden of disease. However, it is also crucial to comprehend and employ survival rate, which is another important descriptive indicator of disease burden and widely used in the evaluation of cancer prognosis. Survival data are available from three sources: clinical studies, hospital-based follow-up data, and population-based followup data ${ }^{[4]}$. Interpretations of the outcomes of each source are different. The population-based follow-up data include the survival information of all patients in the population, which can reflect the cancer survival status of the entire population. Population-based survival data usually exclude death certificate only (DCO) and autopsy cases during analysis because evidence of diagnosis is weak.

Cancer registries are the premise and foundation of cancer prevention and control. They help obtain comprehensive, accurate, and timely information on the incidence, mortality, survival, and other factors related to cancer in the population ${ }^{[4]}$. Survival analysis can be conducted with these data, and provide valuable indicators such as population-based relative survival rate (RSR) for the effectiveness of cancer control and reflect the prospects of cure in a country or region ${ }^{[5]}$. To describe the global pattern, chronological changes, and enable comparisons between different populations or regions, this review collected all available population-based survival rates of primary liver cancer in different populations.

\section{METHODS}

\section{Data source}

A literature search of related studies from 1 January 2000 to 30 April January 2020 was conducted using the databases of CNKI, Wanfang Data, PubMed, Web of Science, EMBASE and SEER, with the following keywords: "liver cancer", "hepatocellular carcinoma", "HCC", "population-based survival studies", "relative survival", "observed survival" "cancer registry". Two researchers collected the data independently according to the search criteria, and 129 articles were retrieved by titles and abstracts. After screening with the following criteria: (1) provided RSR or observed survival rate (OSR) of patients with primary liver cancer; and (2) data were population-based or from cancer registries, and excluding duplicate, incomplete or unavailable articles. The final analysis included 53 studies, 9 of which were in Chinese and the remaining 44 were in English [Figure 1].

\section{Statistical analysis}

Estimates of one to five-year RSRs from the published studies were extracted. We used overall and agestandardized 5-year RSR mainly to describe and compare different countries or regions, age groups, and 


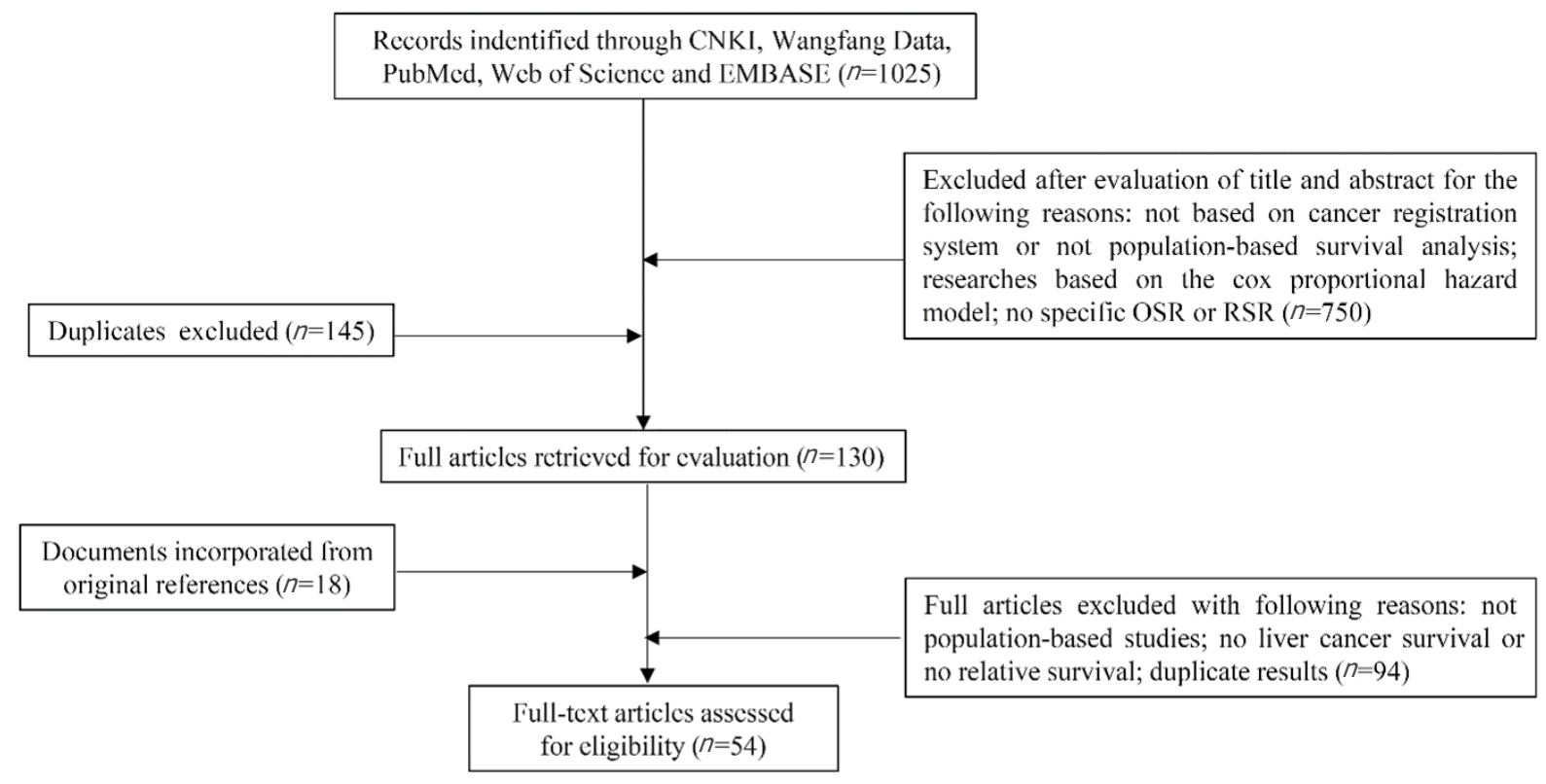

Figure 1. Study selection process. OSR: observed survival rate; RSR: relative survival rate

gender. Most of the included publications provided the age-standardized relative survival rates which were extracted. SPSS 22.0 and Excel 2016 were used for data management and analysis.

\section{RESULTS}

\section{Global pattern and trend}

Table 1 shows the sex-specific overall 5-year RSRs from Korea ${ }^{[6-11]}$, Japan ${ }^{[12]}$, Singapore ${ }^{[13]}$, USA $^{[14,15]}$, and Europe ${ }^{[14,16-22]}$. Table 2 shows the sex-specific age-standardized 5 -year RSRs mainly from Singapore ${ }^{[13]}$ and Europe ${ }^{[16,19,23,24]}$. In addition, the overall 10-year RSRs in Japan during 2002-2006 were 9.6\% for men and $9.1 \%$ for women. It can be inferred from Tables 1 and 2 that although the 5-year RSRs of PLC in women is higher than that in men in most countries or regions, the difference is not obvious. The greatest difference in overall 5-year RSRs between male and female was observed in Scotland during 2005-2007 (4.4\% for male and $10.6 \%$ for female $)^{[18]}$, followed by the USA during $1986-1988$ (3.5\% for male and $8.5 \%$ for female $)^{[14]}$. In age-standardized 5-year RSRs, the greatest difference was observed in Norway during 1990-1994 and 19941998 (both $5.0 \%$ for male and $11.0 \%$ for female ${ }^{[24]}$. When comparing Tables 1 and 2 to determine whether age-standardization of 5-year RSRs has an effect on outcomes, the dissimilarity is not striking. In Europe (1990-1994) ${ }^{[16]}$, after age standardization, the 5-year RSRs in both men and women decreased; in France $(1989-1997)^{[19]}$, the indicator in men increased, but remained the same in women. Besides, some studies have provided one to five-year RSRs or one and five-year age-standardized RSRs, as the details displayed in Supplementary Tables 1 and 2.

Figure 2A and B demonstrate age-standardized and overall 5-year RSRs since 1974 of PLC respectively, in selected countries and regions from Asia ${ }^{[6-12,25-28]}$, North America ${ }^{[11,12,14,15,29-32]}$, Europe ${ }^{[14,16,17,19,21,22,33-36]}$, and Africa ${ }^{[37,38]}$. Figure $2 \mathrm{~A}$ revealed that the highest age-standardized 5 -year RSR was $18.0 \%$ and observed in Italy during $2005-2007^{[36]}$, followed by Canada during $2004-2006^{[30]}$, which was $17.0 \%$. The lowest agestandardized 5-year RSR was $2.3 \%$ observed in Iceland during 1995-1999 ${ }^{[17]}$. Figure $2 \mathrm{~B}$ showed that in the 1980s and before, the overall 5-year RSRs in all regions was lower than 5\%, with the lowest being the USA $(1977-1981)^{[32]}$ and Vaud of Switzerland (1984-1988) ${ }^{[22]}$, both of which were $2.0 \%$. However, after entering the 21st century, the 5-year RSRs in most regions have improved greatly. In general, the survival rates have 
Table 1. Population-based sex-specific overall 5-year relative survival rates of primary liver cancer in selected countries

\begin{tabular}{|c|c|c|c|c|}
\hline \multirow{2}{*}{ Region } & & \multirow{2}{*}{ Year } & \multicolumn{2}{|c|}{ 5-year RSR (\%) } \\
\hline & & & Male & Female \\
\hline \multirow[t]{9}{*}{ Korea $^{[6-11]}$} & & 1993-1995 & 9.9 & 13.6 \\
\hline & & 1996-2000 & 12.9 & 14.2 \\
\hline & & $2001-2005$ & 20.1 & 20.3 \\
\hline & & 2007-2011 & 28.5 & 28.7 \\
\hline & & $2005-2009$ & 25.1 & 25.1 \\
\hline & & 2008-2012 & 30.4 & 29.3 \\
\hline & & $2010-2014$ & 33.1 & 31.9 \\
\hline & & $2012-2016$ & 35.2 & 32.7 \\
\hline & & $2006-2010$ & 26.6 & 26.7 \\
\hline \multirow[t]{2}{*}{$J^{J a p a n}{ }^{[12]}$} & & 1993-1996 & 21.0 & 21.8 \\
\hline & & 1997-1999 & 23.7 & 21.8 \\
\hline \multirow[t]{9}{*}{ USA $^{[14,15]}$} & & 1983-1985 & 2.7 & 6.2 \\
\hline & & 1986-1988 & 3.5 & 8.5 \\
\hline & & 1989-1991 & 3.4 & 7.0 \\
\hline & & 1992-1994 & 4.7 & 5.3 \\
\hline & & 1996-1998 & 8.3 & 9.1 \\
\hline & & 1999-2001 & 10.9 & 12.1 \\
\hline & & $2002-2004$ & 14.9 & 14.7 \\
\hline & & 2005-2009 & 17.7 & 17.3 \\
\hline & & $2010-2016$ & 20.8 & 20.9 \\
\hline \multirow[t]{6}{*}{ Europe $e^{[14,16,17]}$} & & 1983-1985 & 2.8 & 5.3 \\
\hline & & $1986-1988$ & 3.7 & 5.2 \\
\hline & & 1989-1991 & 5.3 & 6.0 \\
\hline & & 1990-1994 & 7.0 & 7.0 \\
\hline & & 1992-1994 & 7.2 & 7.0 \\
\hline & & 1995-1999 & 8.9 & 8.4 \\
\hline \multirow[t]{5}{*}{ Scotland $d^{[18]}$} & & 1985-1989 & 0.4 & 0.5 \\
\hline & & 1990-1994 & 2.2 & 5.4 \\
\hline & & 1995-1999 & 5.5 & 7.1 \\
\hline & & $2000-2004$ & 8.7 & 8.7 \\
\hline & & $2005-2007$ & 4.4 & 10.6 \\
\hline \multirow[t]{4}{*}{ France } & Total $^{[19]}$ & 1989-1997 & 7.0 & 9.0 \\
\hline & Côte-d'Or, Burgundy ${ }^{[20]}$ & 1976-1985 & 1.1 & 2.0 \\
\hline & & $1986-1995$ & 4.6 & 2.6 \\
\hline & & $1996-2005$ & 10.3 & 10.3 \\
\hline Spain ${ }^{[21]}$ & & $2000-2007$ & 13.8 & 10.6 \\
\hline \multirow[t]{3}{*}{ Switzerland ${ }^{[22]}$} & Vaud & $1974-1978$ & - & 22.0 \\
\hline & & $1984-1988$ & 3.0 & - \\
\hline & & 1989-1993 & 8.0 & 7.0 \\
\hline
\end{tabular}

-: No report or non-available in the original articles; RSR: relative survival rate

gradually increased in all regions with time. Korea's growth was the most obvious, rising from $10.7 \%$ in the early 1990 s to $34.6 \%$ during $2012-2016^{[6-11]}$.

Time changes in survival rates for liver cancer were also reviewed in our study. Figure 3 shows the agestandardized 5-year RSRs of PLC in specific regions in Europe ${ }^{[36]}$ at a specific calendar period. It was confirmed again in Figure 3 that the RSRs of PLC have been increasing over time. During three identical periods, we found that the rates were almost higher in Southern Europe (12.0\% during 1999-2001, 14.0\% during 2002-2004, 17.0\% during 2005-2007), but consistently poorest in Eastern Europe (6.0\% during 19992001 and $2002-2004,7.0 \%$ in 2005-2007).

Figure 4 shows a comparison of age-specific relative survival rates of PLC. Because some reports did not provide age-specific survival data, and some reports adopted different age groups, Figure 4 demonstrated 
Table 2. Population-based sex-specific age-standardised 5-year relative survival rates of primary liver cancer in selected countries

\begin{tabular}{|c|c|c|c|}
\hline \multirow{2}{*}{ Region } & \multirow{2}{*}{ Year } & \multicolumn{2}{|c|}{ Age-standardised 5-year RSR (\%) } \\
\hline & & Male & Female \\
\hline \multirow[t]{5}{*}{ Singapore ${ }^{[13]}$} & $1968-1972$ & 5.0 & 3.0 \\
\hline & 1973-1977 & 1.0 & 6.0 \\
\hline & 1978-1982 & 3.0 & 8.0 \\
\hline & $1983-1987$ & 2.0 & 3.0 \\
\hline & 1988-1992 & 3.0 & 2.0 \\
\hline Europe $^{[16]}$ & 1990-1994 & 6.2 & 6.7 \\
\hline Austria $^{[16]}$ & 1990-1994 & 7.0 & - \\
\hline Czech Republic ${ }^{[16]}$ & 1990-1994 & 1.1 & 3.4 \\
\hline \multirow[t]{4}{*}{ Denmark $[16,23,24]$} & 1989-1993 & 3.0 & 3.0 \\
\hline & 1990-1994 & - & 2.3 \\
\hline & 1994-1998 & 4.0 & 4.0 \\
\hline & $1999-2003$ & 3.0 & 5.0 \\
\hline England $^{[16]}$ & $1990-1994$ & 6.1 & 7.2 \\
\hline Estonia $^{[16]}$ & 1990-1994 & 5.5 & - \\
\hline \multirow[t]{4}{*}{ Finland $d^{[16,23,24]}$} & 1989-1993 & 4.0 & 5.0 \\
\hline & 1990-1994 & 3.9 & 4.4 \\
\hline & 1994-1998 & 7.0 & 7.0 \\
\hline & $1999-2003$ & 8.0 & 8.0 \\
\hline \multirow[t]{3}{*}{ Iceland $^{[23,24]}$} & 1989-1993 & 14.0 & - \\
\hline & 1994-1998 & 7.0 & - \\
\hline & $1999-2003$ & 7.0 & - \\
\hline \multirow[t]{2}{*}{ France $^{[16,19]}$} & 1989-1997 & 8.0 & 9.0 \\
\hline & 1990-1994 & 6.9 & - \\
\hline Germany $^{[16]}$ & 1990-1994 & - & 3.8 \\
\hline Italy ${ }^{[16]}$ & 1990-1994 & 6.2 & 8.6 \\
\hline The Netherlands ${ }^{[16]}$ & 1990-1994 & 6.2 & 5.8 \\
\hline \multirow[t]{4}{*}{ Norway $^{[16,23,24]}$} & 1989-1993 & 6.0 & 8.0 \\
\hline & 1990-1994 & 2.1 & 3.2 \\
\hline & 1994-1998 & 5.0 & 11.0 \\
\hline & $1999-2003$ & 5.0 & 11.0 \\
\hline Poland ${ }^{[16]}$ & 1990-1994 & - & 1.3 \\
\hline Scotland ${ }^{[16]}$ & 1990-1994 & - & 4.8 \\
\hline Slovakia ${ }^{[16]}$ & 1990-1994 & - & 1.8 \\
\hline Slovenia ${ }^{[16]}$ & 1990-1994 & - & 4.9 \\
\hline Spain ${ }^{[16]}$ & 1990-1994 & 10.4 & 11.6 \\
\hline \multirow[t]{4}{*}{ Sweden ${ }^{[16,23,24]}$} & 1989-1993 & 5.0 & 3.0 \\
\hline & 1990-1994 & 2.9 & 3.1 \\
\hline & 1994-1998 & 6.0 & 7.0 \\
\hline & $1999-2003$ & 7.0 & 8.0 \\
\hline Switzerland ${ }^{[16]}$ & 1990-1994 & 5.9 & - \\
\hline Wales $^{[16]}$ & 1990-1994 & 5.1 & 6.3 \\
\hline
\end{tabular}

-: No reports or non-available in the original articles; RSR: relative survival rate

the age-specific 5-year RSRs from Europe ${ }^{[16,17,36]}, \operatorname{USA}^{[15]}$ Japan $^{[26]}$, Canada ${ }^{[30,31]}$, Korea ${ }^{[11]}$, and China ${ }^{[39-41]}$ in the period between 1990-2010. The 5-year RSRs decreased with age. The rates of patients aged 15-44, followed by those aged 45-54, were higher than other age groups, while the prognosis of patients aged 75 or older was poor. In the age groups of 35-44 and 45-54, the rate in Canada (2004-2006) ${ }^{[30]}$ was markedly higher than that in other regions. In the age 65-74 group, the rate of Korea (2006-2010) ${ }^{[11]}$ was markedly higher than that in other regions, and that in those age 75 or older, was highest in the Zhejiang Province $(2005-2010)^{[41]}$ of China compared to other regions or countries. Of note however, some reports estimate RSRs after excluding DCO and autopsy cases ${ }^{[11-14,18,21,22,24,26,28,30,31,35,36,39,40,42-45]}$. 
A

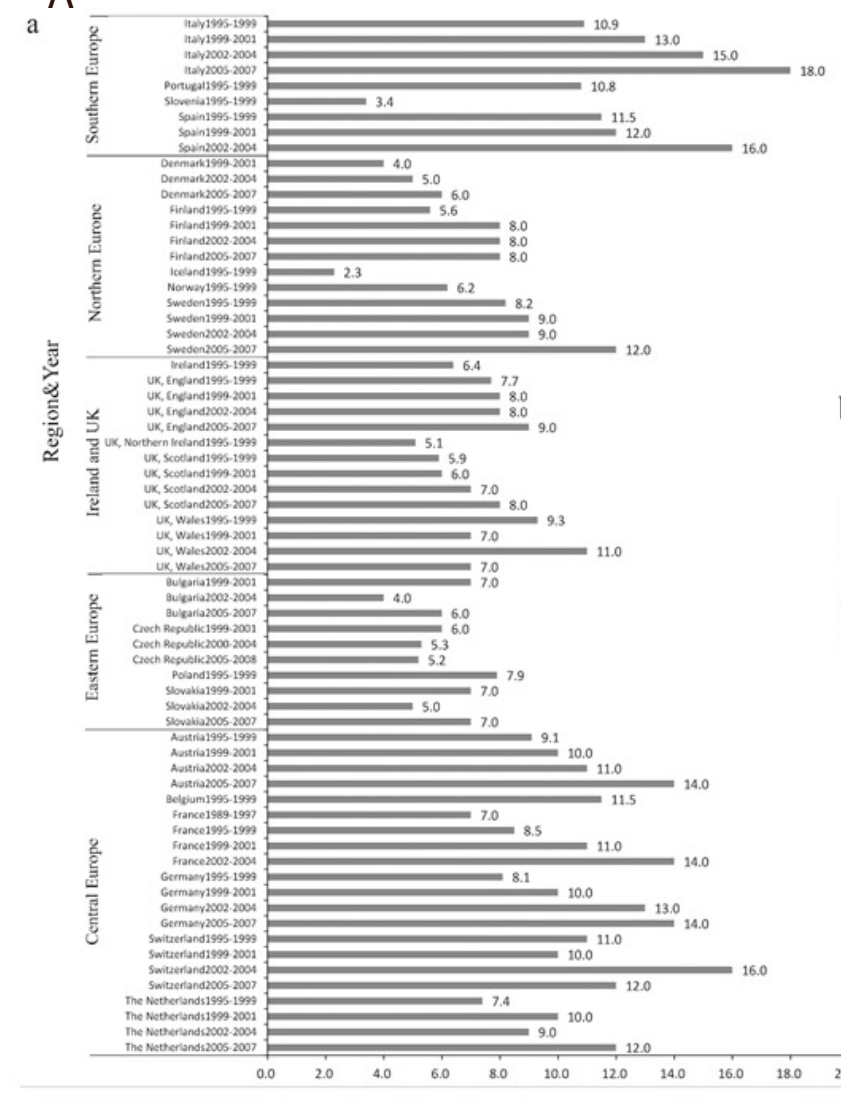

$\mathrm{b}$

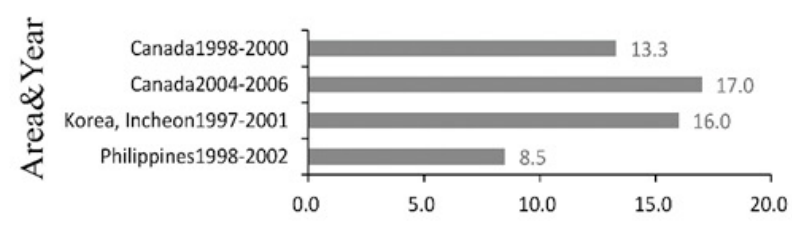

B

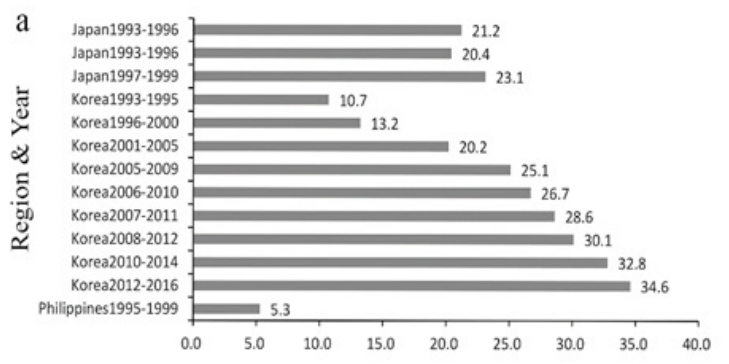

b USA1977-1981 2.0 USA1982-1986 4.0 \begin{tabular}{ll} 
USA1983-1985 & 3.7 \\
USA1986-1988 & -4.9 \\
\hline
\end{tabular}

\begin{tabular}{r|r}
4.9 \\
USA1986-1988 \\
USA1987-1991
\end{tabular}

USA1989-1991 4.4

4.9

USA1992-1996 6.0

USA1996-2003 10.8

USA2002-2008 15.2

USA2006-2012
USA2010-2016.

USA2010-2016

Canada1992-1994 10.120

Canada1998-2000 13.7

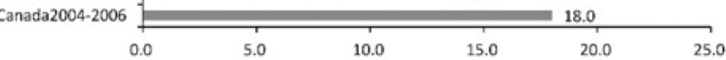

C
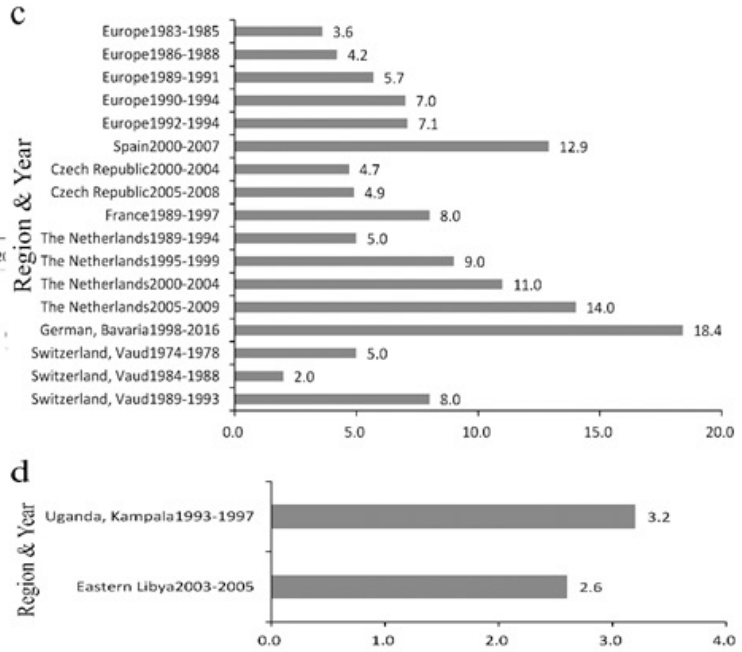

Figure 2. Age-standardised and overall 5-year relative survival rates of primary liver cancer in some selected countries during 19742016. A: Age-standardised 5-year relative survival rates (a: Europe ${ }^{\star[17,19,35,36]}$; b: other regions ${ }^{[27,28,30,31]}$ ); B: overall 5-year relative survival rates (a: Europe ${ }^{[14,16,19,21,22,33-35]} ;$ b: Asia ${ }^{[6-12,25,26]}$; c: North America ${ }^{[11,12,14,15,29-32]}$; d: Africa ${ }^{[37,38]}$ ). ${ }^{\star}$ The divisions of Europe refer to the EUROCARE report

\section{Liver cancer survival in China}

Table 3 shows the details of the population-based overall and age-standardized 5-year RSRs of PLC in some areas in China. It mainly includes the survival of PLC in the nation ${ }^{[46]}$, Beijing ${ }^{[45]}$, Shanghai ${ }^{[39]}$, Zhejiang Province $^{[41]}$, Liaoning Province ${ }^{[28]}$, Taiwan ${ }^{[47]}$, Hong Kong ${ }^{[28]}$, Haining and Jiashan (Zhejiang Province) ${ }^{[48]}$, Cixian (Hebei Province) ${ }^{[49,50]}$, Huaian (Jiangsu Province) ${ }^{[51]}$, Qidong (Jiangsu Province) ${ }^{[40,52]}$, and Jintan district (Changzhou, Jiangsu Province) ${ }^{[53]}$. Among them, cases of DCO were explicitly excluded in the reports of Shanghai ${ }^{[39]}$, Qidong of Jiangsu ${ }^{[40]}$, Haining, and Jiashan of Zhejiang ${ }^{[48]}$, and Liaoning ${ }^{[28]}$.

As shown in Table 3, the 5-year RSRs of PLC improved gradually over time. The age-standardized 5-year RSRs of liver cancer patients in China (2003-2015) are lower than that of Korea and Japan for a similar time period. For the overall 5-year RSRs, gender difference was not found in our review as the survival rates of liver cancer in women were not consistently higher than that in men. The highest overall 5-year RSR of 


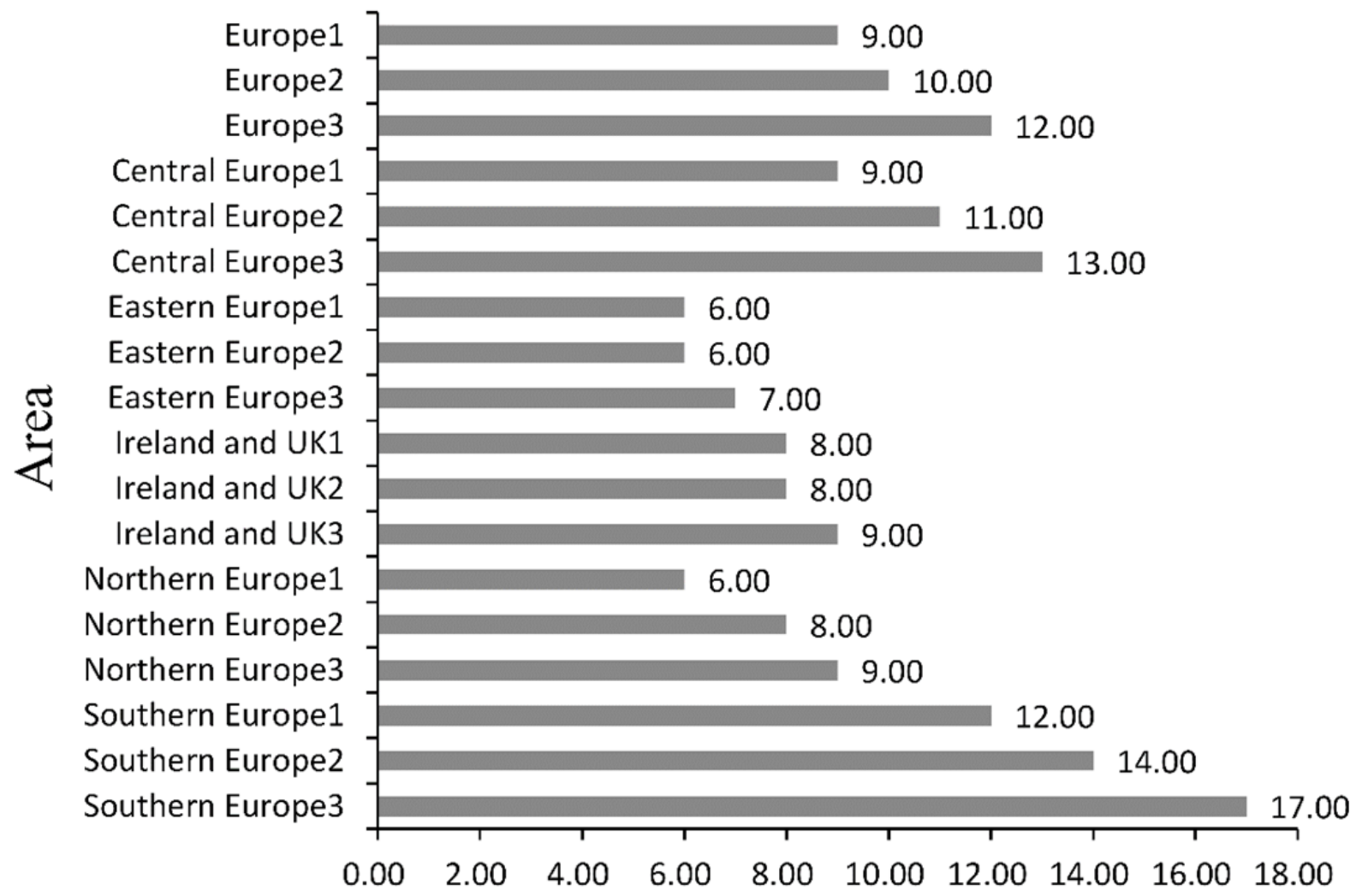

Figure 3. The age-standardised 5-year relative survival rates of primary liver cancer in different areas of Europe*, 1999-2007 ${ }^{[36]}$. 1: 19992001; 2:2002-2004; 3: 2005-2007. ${ }^{\star}$ The divisions of Europe refer to the EUROCARE report

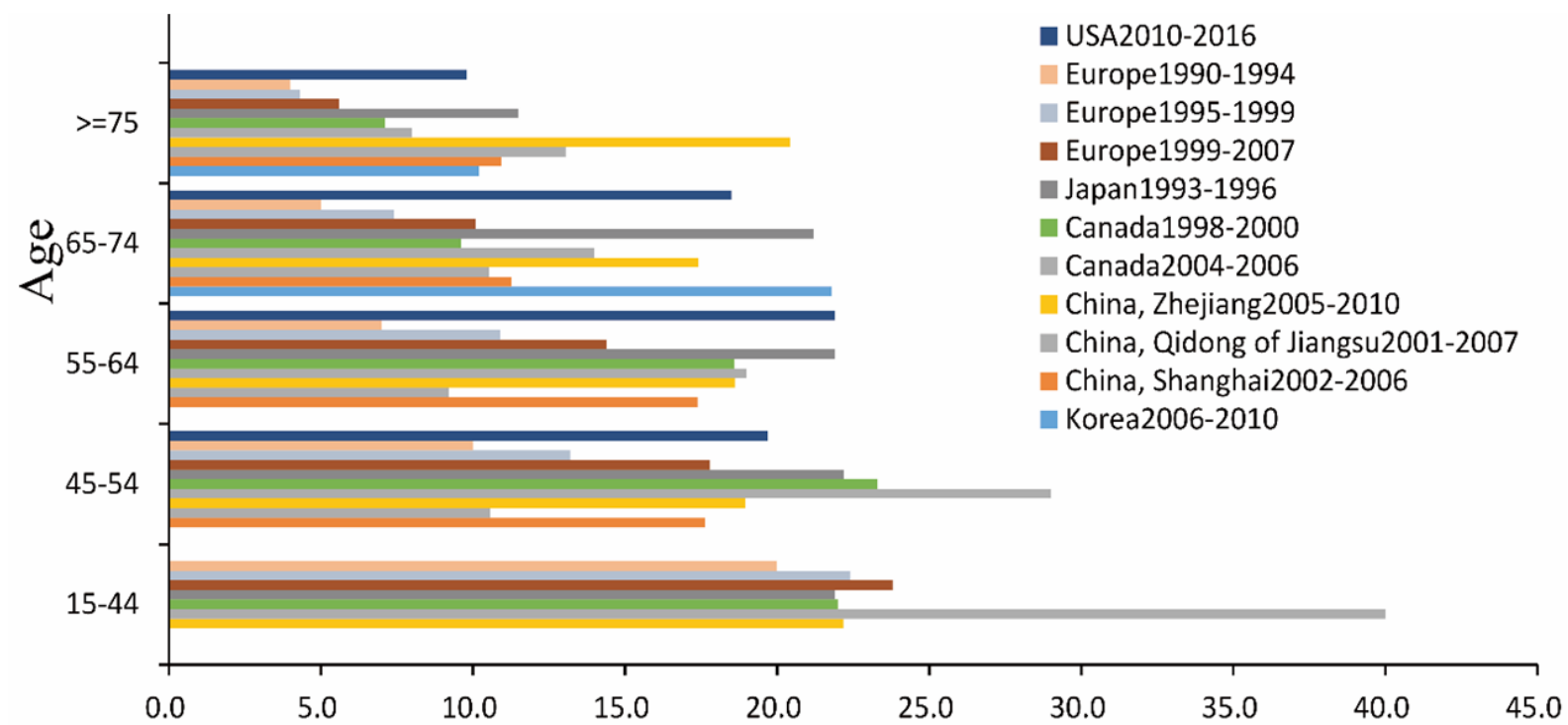

Figure 4. Age-specific 5-year relative survival rates of primary liver cancer in different years in some selected countries and regio $\mathrm{ns}^{[11,15-17,26,30,36,39-41]}$

28.9\% was in Taiwan during 2004-2008, which was $28.1 \%$ and $31.7 \%$ in men and women respecitvely ${ }^{[47]}$. Since 2000, the overall 5-year RSR of Cixian (Hebei Province) was the lowest, at only $4.2 \%$ in 2000-2002 ${ }^{[49]}$. 
Table 3. Population-based overall and age-standardised 5-year relative survival rates of PLC in some areas of China

\begin{tabular}{|c|c|c|c|c|c|c|c|c|c|}
\hline \multirow{2}{*}{ Area } & & & \multirow{2}{*}{ Year } & \multicolumn{3}{|c|}{ 5-year RSR (\%) } & \multicolumn{3}{|c|}{ Age-standardised 5-year RSR (\%) } \\
\hline & & & & Total & Male & Female & Total & Male & Female \\
\hline \multirow[t]{4}{*}{ China $^{[46]}$} & & & $2003-2005$ & - & - & - & 10.1 & 10.2 & 10.3 \\
\hline & & & $2006-2008$ & - & - & - & 10.1 & 10.0 & 11.0 \\
\hline & & & 2009-2011 & - & - & - & 9.8 & 9.8 & 10.7 \\
\hline & & & $2012-2015$ & - & - & - & 12.1 & 12.2 & 13.1 \\
\hline \multirow[t]{17}{*}{ East China } & Shanghai ${ }^{[39]}$ & & $2002-2006$ & 15.5 & 16.0 & 14.8 & - & - & - \\
\hline & Zhejiang & Total $^{[41]}$ & $2005-2010$ & 19.1 & 19.5 & 18.0 & - & - & - \\
\hline & & Haining and & $2003-2006$ & 10.3 & 9.8 & 11.4 & 10.2 & - & - \\
\hline & & Jiashan $^{[48]}$ & $2007-2010$ & 8.9 & 9.5 & 7.9 & 9.0 & - & - \\
\hline & & & 2011-2014 & 10.6 & 11.3 & 8.9 & 10.2 & - & - \\
\hline & Jiangsu & Huaian $^{[51]}$ & 2010 & 8.4 & 8.9 & 6.9 & - & - & - \\
\hline & & $\begin{array}{l}\text { Jintan District of } \\
\text { Changzhou }^{[53]}\end{array}$ & $2012-2013$ & 11.6 & - & - & - & - & - \\
\hline & & Qidong $^{[40,52]}$ & $1972-2011$ & 4.7 & 4.5 & 5.4 & - & - & - \\
\hline & & & 1973-1977 & 2.8 & - & - & - & - & - \\
\hline & & & 1978-1982 & 1.4 & - & - & - & - & - \\
\hline & & & 1983-1987 & 2.6 & - & - & - & - & - \\
\hline & & & 1988-1992 & 4.7 & - & - & - & - & - \\
\hline & & & 1993-1997 & 4.7 & - & - & - & - & - \\
\hline & & & 1998-2002 & 5.1 & - & - & - & - & - \\
\hline & & & $2001-2007$ & 10.0 & 9.8 & 10.6 & - & - & - \\
\hline & & & $2003-2007$ & 7.1 & - & - & - & - & - \\
\hline & Taiwan ${ }^{[47]}$ & & $2004-2008$ & 28.9 & 28.1 & 31.7 & 27.6 & 27.0 & 31.5 \\
\hline \multirow[t]{4}{*}{ North China } & Beijing $^{[45]}$ & & 1982-1983 & - & 2.2 & 2.4 & - & - & - \\
\hline & & & $1987-1988$ & - & 3.4 & 5.3 & - & - & - \\
\hline & Hebei ${ }^{[49,50]}$ & Cixian & $2000-2002$ & 4.2 & - & - & - & - & - \\
\hline & & & $2003-2013$ & 7.6 & 7.1 & 8.7 & - & - & - \\
\hline South China & Hong Kong ${ }^{[28]}$ & & 1996-2001 & - & - & - & 22.4 & - & - \\
\hline Northeast China & Liaoning $^{[28]}$ & & 2000-2002 & - & - & - & 10.7 & 8.8 & 15.2 \\
\hline
\end{tabular}

-: No reports or non-available in the original articles; RSR: relative survival rate

\section{DISCUSSION}

Survival data based on clinical trials, hospital-based follow-up studies, and population-based cancer registration are disparate in their aims, methods of survival estimation, and application. This study collected overall or age-standardized RSRs of liver cancer worldwide so that we can describe the prognosis of liver cancer in the general population, and make comparisons between different countries and regions. All publications in the study were from the cancer registries or population-based survival analysis, which aimed to provide valuable information for epidemiologists, basic scientists, oncologists, and clinical physicians in liver cancer research.

The aim of clinical trials and hospital-based follow-up studies are quite different from that of populationbased survival studies. The survival obtained from clinical trials or studies comes from the evaluation of certain therapeutics, and generally adopts overall survival (defined as the date from randomization to death from any cause) and progression-free survival (defined as the date from randomization until progression or death from any cause) as endpoints. For instance, a randomized, phase 3 clinical trial published in the New England Journal of Medicine evaluated cabozantinib as compared with placebo in previously treated patients with advanced hepatocellular carcinoma, and demonstrated that cabozantinib treatment significantly prolonged survival in patients with longer overall survival and progression-free survival (median overall survival and median progression-free survival were 10.2 months and 5.2 months, respectively) compared to placebo (8.0 months and 1.9 months, respectively $)^{[54]}$. Hospital-based survival or follow-up studies rely on hospital-based cancer follow-up or registries that collect survival information 
of patients who have been hospitalized, which reflects the service's capacity and treatment effects in a particular department. For example, using follow-up data in a hospital's registry, a study in Qidong of Jiangsu Province from China ${ }^{[55]}$ calculated the 5-year observed survival rate of patients with liver cancer from 2002 to 2016 to be $14.6 \%$ [Supplementary Table 3], which was higher than the population-based OSR of 8.9\% reported in the general population of Qidong during 2001-2007. For hospital-based survival, the follow-up time starts from the first hospitalization date, while the population-based cancer registry starts from the date of diagnosis of cancer. However, according to the data in China, the survival rates of PLC in the more developed areas such as Shanghai and Zhejiang were higher than that of other areas and the national average during the similar period, and studies have additionally supported the observation that the survival rates of PLC in urban areas were higher than that in the rural areas for the same period.

A common reason to study population-based cancer survival is to estimate the net survival, a measure of patient survival following primary cancer in the absence of other causes of death ${ }^{[56]}$, which can be obtained by calculating disease-specific survival. Since the estimation of net survival must rely on complete and accurate information on the cause of death, which is often difficult to obtain, an alternative indicator $\mathrm{RSR}^{[5]}$ - can be used. RSR is defined as the ratio of the observed survival rate (where all causes of deaths are considered as events) to the expected survival rate (which is estimated from national population life tables stratified by sex, age, and calendar period) in the general population with the same distribution of key demographic factors (sex, age, calendar, period, and country). It provides a measure of the excess mortality hazard experienced by cancer patients, irrespective of whether the excess mortality is directly or indirectly attributable to the cancer ${ }^{[56]}$ and enables direct comparison of survival rates between different populations or regions by eliminating the effects of age, gender, ethnicity, and calendar period on cancer survival to some extent. In addition, to further eliminate the effect of age structure, international comparisons of RSRs ought to use age-standardized relative survival ${ }^{[57]}$.

It is apparent from our review then that the prognosis of PLC has shown continuous improvement overtime, whether in China or around the world. Over the past decades, numerous changes in clinical practice, public health, and social economy may affect the survival of PLC. For instance, advances in imaging diagnosis, clinical treatment such as chemoembolization, ablation, and surgical resection techniques, increased surveillance and screening for early-stage disease and anti-cancer health education, the improvement of socio-economic status (SES) and the transformation of peoples' health consciousness and lifestyles ${ }^{[39,58,59]}$. However, it is these factors that can improve survival rates that may lead to regional disparity in survival rates of PLC as well, because of their varying degrees of development between different regions. Globally, the 5-year RSRs in Africa such as Eastern Libya and Uganda Kampala are much poorer than in the countries of Europe and North America during the same time period, and 5-year RSRs of PLC were also varied across regions in Europe. Studies have shown that people from the highest SES have better survival outcomes compared to those in the lowest SES ${ }^{[60-62]}$. The low SES and the attendant delayed diagnosis and treatment, unfair distribution of medical resources, incomplete medical insurance systems, lack of health education, and other factors will all affect cancer survival.

The data we have summarized from the literature implied that there are gender and age disparities in liver cancer survival. For example, in the majority of countries and regions, the prognosis of liver cancer in women was better than men, although the situation was not systematic. Therefore, it is inappropriate to draw the conclusion that the prognosis of women with PLC is better than men. Gender-specific distinctions in the survival rate of PLC require more population-based follow-up studies. In terms of the age at diagnosis, survival was highest among patients in the 35-44 age group, followed by the 45-54 age group, and lowest for the 75 or older age group. This might have been due to the presence of comorbidities and various chronic diseases in the aged patients that reduced their tolerance of cancer treatments or affected physicians' decisions for treatment options, as compared to younger patients ${ }^{[63-65]}$. In addition, studies have 
suggested that the proportion of late-diagnosis of PLC in the older age group was higher, resulting in poor long-term survival ${ }^{[39]}$.

When comparing survival rates in different countries, times, or populations, etc., the following points need to be considered. Firstly, the relative survival rate was the only indicator analyzed in this review. However, descriptive indicators of cancer survival also include observed survival rate (all the OSRs collected were showed in Supplementary Table 3), cause-specific survival, etc. The estimation methods and their interpretations are completely different and cannot be substituted for each other. Next, close attention to additional comorbidities or variables (such as age, gender, ethnicity, etc.) used in survival rate estimation in the study is required. As in this review, some studies excluded patients aged under 15 or 20 during analy $\operatorname{sis}^{[11,18,21,30,34,35,44,47]}$. Thirdly, it should be noted whether DCO cases or autopsy cases were excluded from the analysis, which would affect outcomes.

In conclusion, we summarized one to five-years RSRs of liver cancer, which were markedly distinct between different regions or periods in the same region. This implied that the region, period, and age might affect the survival rate of PLC; however, whether gender is a relevant factor remains to be studied. Therefore, more attention should be drawn to PLC prevention and screening, in particular, must be developed and implemented. Epidemiological, basic, and clinical studies of PLC have a long way to go still.

\section{DECLARATIONS}

\section{Authors' contributions}

Conducted the study and collected publications and abstract data and wrote the first draft: Jiang YF

Double check the collected publications and abstract data: Li ZY

Reviewed and approved the final version of the paper: Jiang YF, Li ZY, Ji XW, Shen QM, Tuo JY, Yuan HY, Xiang YB

Primary responsibility for final content, designed the research study and obtained funding: Xiang YB

\section{Availability of data and materials}

Not applicable.

\section{Financial support and sponsorship}

This work was supported by the National Key Project of Research and Development Program of China (No. 2016YFC1302503); the National Key Basic Research Program of China "973 Program" (No. 2015CB554000); the State Key Project Specialized for Infectious Diseases of China (No. 2008ZX10002-015 and No. 2012ZX10002008-002).

\section{Conflicts of interest}

All authors declared that there are no conflicts of interest.

\section{Ethical approval and consent to participate}

Not applicable.

\section{Consent for publication}

Not applicable.

\section{Copyright}

(c) The Author(s) 2020. 


\section{REFERENCES}

1. Bray F, Ferlay J, Soerjomataram I, Siegel RL, Torre LA, et al. Global cancer statistics 2018: GLOBOCAN estimates of incidence and mortality worldwide for 36 cancers in 185 countries. CA Cancer J Clin 2018;68:394-424.

2. Ying Q, Wang Y. Global prevalence and trend of liver cancer. China Cancer 2020;29:185-91.

3. Howlader N, Noone A, Krapcho M, Miller D, Brest A, et al. SEER cancer statistics review, 1975-2016, National Cancer Institute. In: Bethesda MD, editor. Based on November 2018 SEER data submission posted to the SEER web site, April 2019. Available from: https:// seer.cancer.gov/csr/1975 2016/. [Last accessed on 3 Jul 2020]

4. Cancer Hospital Chinese Academy of Medical Science. Chinese Guideline for Cancer Registration (2016)ed. Beijing: People's Medical Publishing House(PMPH) Pub; 2016. pp. 33-75.

5. Hakulinen T. Cancer survival corrected for heterogeneity in patient withdrawal. Biometrics 1982;38: 933-42.

6. Jung KW, Park S, Kong HJ, Won YJ, Lee JY, et al. Cancer statistics in Korea: incidence, mortality, survival, and prevalence in 2009. Cancer Res Treat 2012;44:11-24.

7. Jung KW, Won YJ, Kong HJ, Oh CM, Lee DH, et al. Cancer statistics in Korea: incidence, mortality, survival, and prevalence in 2011. Cancer Res Treat 2014;46:109-23.

8. Jung KW, Won YJ, Kong HJ, Oh CM, Cho H, et al. Cancer statistics in Korea: incidence, mortality, survival, and prevalence in 2012. Cancer Res Treat 2015;47:127-41.

9. Jung KW, Won YJ, Oh CM, Kong HJ, Lee DH, et al. Cancer statistics in Korea: incidence, mortality, survival, and prevalence in 2014. Cancer Res Treat 2017;49:292-305.

10. Jung KW, Won YJ, Kong HJ, Lee ES. Cancer statistics in Korea: incidence, mortality, survival, and prevalence in 2016. Cancer Res Treat 2019;51:417-30.

11. Jung KW, Won YJ, Kong HJ, Oh CM, Shin A, et al. Survival of korean adult cancer patients by stage at diagnosis, 2006-2010: national cancer registry study. Cancer Res Treat 2013;45:162-71.

12. Matsuda T, Ajiki W, Marugame T, Ioka A, Tsukuma H, et al. Population-based survival of cancer patients diagnosed between 1993 and 1999 in Japan: a chronological and international comparative study. Jpn J Clin Oncol 2011;41:40-51.

13. Chia KS, Du WB, Sankaranarayanan R, Sankila R, Seow A, et al. Population-based cancer survival in Singapore, 1968 to 1992 : an overview. Int J Cancer 2001;93:142-7.

14. Capocaccia R, Sant M, Berrino F, Simonetti A, Santi V, et al. Hepatocellular carcinoma: trends of incidence and survival in Europe and the United States at the end of the 20th century. Am J Gastroenterol 2007;102:1661-70.

15. Howlader N, Noone AM, Krapcho M, Miller D, Brest A, et al. SEER Cancer Statistics Review, 1975-2017, National Cancer Institute. Available from: https://seer.cancer.gov/csr/1975_2017/. [Last accessed on 30 Jun 2020].

16. Sant M, Aareleid T, Berrino F, Bielska Lasota M, et al. EUROCARE-3: survival of cancer patients diagnosed 1990-94--results and commentary. Ann Oncol 2003;14:v61-118.

17. Sant M, Allemani C, Santaquilani M, Knijn A, Marchesi F, et al. EUROCARE-4. Survival of cancer patients diagnosed in 1995-1999. Results and commentary. Eur J Cancer 2009;45:931-91.

18. Dunbar JK, Dillon J, Garden OJ, Brewster DH. Increasing survival of hepatocellular carcinoma patients in Scotland: a review of national cancer registry data. HPB 2013;15:279-85.

19. Bossard N, Velten M, Remontet L, Belot A, Maarouf N, et al. Survival of cancer patients in France: a population-based study from The Association of the French Cancer Registries (FRANCIM). Eur J Cancer 2007;43:149-60.

20. Guiu B, Minello A, Cottet V, Lepage C, Hillon P, et al. A 30-year, population-based study shows improved management and prognosis of hepatocellular carcinoma. Clin Gastroenterol Hepatol 2010;8:986-91.

21. Chirlaque MD, Salmeron D, Galceran J, Ameijide A, Mateos A, et al. Cancer survival in adult patients in Spain. Results from nine population-based cancer registries. Clin Transl Oncol 2018;20:201-11.

22. Levi F, Randimbison L, Te VC, Franceschi S, La Vecchia C. Trends in survival for patients diagnosed with cancer in Vaud, Switzerland, between 1974 and 1993. Ann Oncol 2000;11:957-63.

23. Storm HH, Engholm G, Hakulinen T, Tryggvadottir L, Klint A, et al. Survival of patients diagnosed with cancer in the Nordic countries up to 1999-2003 followed to the end of 2006. A critical overview of the results. Acta Oncol 2010;49:532-44.

24. Klint A, Engholm G, Storm HH, Tryggvadottir L, Gislum M, et al. Trends in survival of patients diagnosed with cancer of the digestive organs in the Nordic countries 1964-2003 followed up to the end of 2006. Acta Oncol 2010;49:578-607.

25. Redaniel MT, Laudico A, Mirasol-Lumague MR, Gondos A, Brenner H. Cancer survival differences between European countries and an urban population from the Philippines. Eur J Public Health 2011;21:221-8.

26. Tsukuma H, Ajiki W, Ioka A, Oshima A. Survival of cancer patients diagnosed between 1993 and 1996: a collaborative study of population-based cancer registries in Japan. Jpn J Clin Oncol 2006;36:602-7.

27. Laudico AV, Mirasol-Lumague MR, Mapua CA, Uy GB, Toral JA, et al. Cancer incidence and survival in Metro Manila and Rizal Province, Philippines. Jpn J Clin Oncol 2010;40:603-12.

28. Li Y, Yu L, Na J, Li S, Liu L, et al. Survival of cancer patients in northeast China: analysis of sampled cancers from population-based cancer registries. Cancer Res Treat 2017;49:1106-13.

29. Jemal A, Ward EM, Johnson CJ, Cronin KA, Ma J, et al. Annual report to the nation on the status of cancer, 1975-2014, featuring survival. J Natl Cancer Inst 2017;109:djx030.

30. Ellison LF, Wilkins K. An update on cancer survival. Health Rep 2010;21:55-60.

31. Ellison LF. Measuring the effect of including multiple cancers in survival analyses using data from the Canadian Cancer Registry. Cancer 
Epidemiol 2010;34:550-5.

32. El-Serag HB, Mason AC, Key C. Trends in survival of patients with hepatocellular carcinoma between 1977 and 1996 in the United States. Hepatology 2001;33:62-5.

33. De Toni EN, Schlesinger-Raab A, Fuchs M, Schepp W, Ehmer U, et al. Age independent survival benefit for patients with hepatocellular carcinoma (HCC) without metastases at diagnosis: a population-based study. Gut 2020;69:168-76.

34. Witjes CD, Karim-Kos HE, Visser O, van den Akker SA, de Vries E, et al. Hepatocellular carcinoma in a low-endemic area: rising incidence and improved survival. Eur J Gastroenterol Hepatol 2012;24:450-7.

35. Pavlik T, Majek O, Buchler T, Vyzula R, Petera J, et al. Trends in stage-specific population-based survival of cancer patients in the Czech Republic in the period 2000-2008. Cancer Epidemiol 2014;38:28-34.

36. Lepage C, Capocaccia R, Hackl M, Lemmens V, Molina E, et al. Survival in patients with primary liver cancer, gallbladder and extrahepatic biliary tract cancer and pancreatic cancer in Europe 1999-2007: results of EUROCARE-5. Eur J Cancer 2015;51:2169-78.

37. El Mistiri M, Salati M, Marcheselli L, Attia A, Habil S, et al. Cancer incidence, mortality, and survival in Eastern Libya: updated report from the Benghazi Cancer Registry. Ann Epidemiol 2015;25:564-8.

38. Gondos A, Brenner H, Wabinga H, Parkin DM. Cancer survival in Kampala, Uganda. Br J Cancer 2005;92:1808-12.

39. Peng H, Zheng Y, Wang CF, Gong YM, Wu CX, et al. Survival analysis of liver cancer between 2002 and 2006 in Shanghai. Chin Oncol 2016:561-8.

40. Chen JG, Zhu J, Zhang YH, Chen YS, Ding LL. Survival of liver cancer during 2001-2007 in Qidong city. Chin J Cancer Prevent Treat 2011;18:568-70.

41. Fei FR, Hu RY, Gong WW, Pan J, Wang M. Analysis of mortality and survival rate of liver cancer in Zhejiang Province in China: a general population-based study. Can J Gastroenterol Hepatol 2019;2019:1074286.

42. Lim GH, Wong CS, Chow KY, Bhalla V, Chia KS. Trends in long-term cancer survival in Singapore: 1968-2002. Ann Acad Med Singapore 2009;38:99-105.

43. Yang YJ, Bae JM. Survival rates of the 5 major cancers in Jeju Island residents, 2000-2001. J Prev Med Public Health 2007;40:213-7.

44. Ito Y, Miyashiro I, Ito H, Hosono S, Chihara D, et al. Long-term survival and conditional survival of cancer patients in Japan using population-based cancer registry data. Cancer Sci 2014;105:1480-6.

45. Wang QJ, Zhu WX, Li L, Xing XM. Cancer survival in urban Beijing. China Cancer 2001;05:17-8.

46. Zeng HM, Chen WQ, Zheng RS, Zhang SW, Ji JS, et al. Changing cancer survival in China during 2003-15: a pooled analysis of 17 population-based cancer registries. Lancet Global Health 2018;6:e555-67.

47. Chiang CJ, Lo WC, Yang YW, You SL, Chen CJ, et al. Incidence and survival of adult cancer patients in Taiwan, 2002-2012. J Formos Med Assoc 2016;115:1076-88.

48. Li H, Yang J, Du L, Li Q, Zhu C, et al. Cancer survival in Haining and Jiashan cancer registry areas of Zhejiang Province. China Cancer 2019;29:14-21.

49. He YT, Zeng Y, Xu H, Song G, Tian G, et al. Survival rate among cancer patients in Cixian county, 2000-2002. Chin J Publ Heal 2011;27:1107-10.

50. Li D, Li D, Song G, Liang D, Chen C, et al. Cancer survival in Cixian of China, 2003-2013: a population-based study. Cancer Med 2018;7:1537-45.

51. Luo S, Pan E, He Y, Zhang Q, Wang C, et al. Analysis of survival rates among residents newly diagnosed with malignant cancers during 2010 in Huai'an City. Chin J Cancer Prevent Treat 2016;23:1049-52.

52. Yao HR, Chen H, Chen JG, Zhu J, Zhang YH. Long-term survival trends for liver cancer in Qidong: 1972 to 2011. Chin J Hepatol 2014;22:921-5.

53. He Y, Zhou X, Lv YL. Analysis of the malignant tumor incidence and survival in Jintan district of Changzhou from 2012 to 2013. Jiangsu J Prevent Med 2019;30:518-21. Available form: http://jsyf.cbpt.cnki.net/WKB2/WebPublication/paperDigest.aspx?paperID=beb308e0c2ea-4038-850f-dd73acc4cb9a. [Last accessed on 3 Jul 2020]

54. Abou-Alfa GK, Meyer T, Cheng AL, El-Khoueiry AB, Rimassa L, et al. Cabozantinib in patients with advanced and progressing hepatocellular carcinoma. N Engl J Med 2018;379:54-63.

55. Chen JG, Chen HZ, Zhu J, Yang YL, Zhang YH, et al. Cancer survival in patients from a hospital-based cancer registry, China. J Cancer 2018;9:851-60.

56. Engholm G, Gislum M, Bray F, Hakulinen T. Trends in the survival of patients diagnosed with cancer in the Nordic countries 1964-2003 followed up to the end of 2006. Material and methods. Acta Oncologica 2010;49:545-60.

57. Corazziari I, Quinn M, Capocaccia R. Standard cancer patient population for age standardising survival ratios. Eur J Cancer 2004;40:2307-16.

58. Jarnagin W, Chapman WC, Curley S, D'Angelica M, Rosen C, et al. Surgical treatment of hepatocellular carcinoma: expert consensus statement. HPB (Oxford) 2010;12:302-10.

59. Sangiovanni A, Del Ninno E, Fasani P, De Fazio C, Ronchi G, et al. Increased survival of cirrhotic patients with a hepatocellular carcinoma detected during surveillance. Gastroenterology 2004;126:1005-14.

60. Yun EH, Lim MK, Oh JK, Park JH, Shin A, et al. Combined effect of socioeconomic status, viral hepatitis, and lifestyles on hepatocelluar carcinoma risk in Korea. Br J Cancer 2010;103:741-6.

61. Artinyan A, Mailey B, Sanchez-Luege N, Khalili J, Sun CL, et al. Race, ethnicity, and socioeconomic status influence the survival of patients with hepatocellular carcinoma in the United States. Cancer 2010;116:1367-77.

62. Jembere N, Campitelli MA, Sherman M, Feld JJ, Lou W, et al. Influence of socioeconomic status on survival of hepatocellular carcinoma 
in the Ontario population; a population-based study, 1990-2009. PLoS One 2012;7:e40917.

63. Brenner H, Arndt V. Recent increase in cancer survival according to age: higher survival in all age groups, but widening age gradient. Cancer Causes Control 2004;15:903-10.

64. Thein HH, Khoo E, Campitelli MA, Zaheen A, Yi Q, et al. Trends in relative survival in patients with a diagnosis of hepatocellular carcinoma in Ontario: a population-based retrospective cohort study. CMAJ Open 2015;3:E208-16.

65. De Angelis R, Sant M, Coleman MP, Francisci S, Baili P, et al. Cancer survival in Europe 1999-2007 by country and age: results of EUROCARE-5-a population-based study. Lancet Oncol 2014;15:23-34. 